\title{
Introduction
}

\section{Situating the biosocial: Empirical engagements with environmental epigenetics from the lab to the clinic}

\author{
Stephanie Lloyd ${ }^{\mathrm{a}}$ and Ruth Müller ${ }^{\mathrm{b}, *}$ \\ aDépartement d'anthropologie, Université Laval, Québec, Canada. \\ ${ }^{\mathrm{b}}$ Munich Center for Technology in Society (MCTS), Technical University of Munich, Munich, Germany. \\ E-mail: ruth.mueller@tum.de \\ ${ }^{*}$ Corresponding author.
}

BioSocieties (2018) 13, 675-680. https://doi.org/10.1057/s41292-017-0094-8;

Published online 18 October 2018

Few life science research fields have met with as ambivalent a response in the social sciences as environmental epigenetics, an emerging yet influential research area exploring the interactions between gene expression and the environment. The conceptual and experimental models emerging from this field have sparked great excitement as well as skepticism in Science \& Technology Studies (STS) and neighboring fields (Pickersgill, 2017), with many researchers expressing both. On the one hand, researchers have interpreted environmental epigenetics as a fundamentally novel thought style in molecular biology that recognizes the importance of the social for the biological and which could create a new "biology without biologism" (Meloni, 2014). On the other hand, researchers also remain skeptical as to whether a shift away from models of health risks and human development based on innate genetic characteristics toward a focus on acquired epigenetic modifications really indicates a less biocentric approach to human biology (Waggonner and Uller, 2015). While a variety of publications have debated these questions, few studies as yet exist that have empirically explored the practices central to epigenetic knowledge production and its relationship to emerging understandings of biology, health, and disease risk. This special issue attends to this important gap in current research.

The nascent field of environmental epigenetics explores how a range of environmental exposures and social experiences, such as toxins, food, and stress, affect gene expression via epigenetic modification. While much epigenetic research is concerned with the basic processes of epigenetic cell differentiation that enable the creation of a multicellular body out of the genome of a single fertilized ovum, environmental epigenetics aims to provide a novel mechanistic link between biological processes and social and material life experiences. This research aims to provide models of how socio-material environments dynamically shape the translation of genetic information into the living structures of our bodies and minds, influencing health and well-being. 
Yet, despite an apparent unification of nature and nurture in epigenetic models of human development, boundary work persists in epigenetics research, maintaining a segregation of 'the biological' and 'the environmental' in the form of separate analyses, respectively, of the genome and the epigenome (Lappé and Landecker, 2015). In effect, epigenetic research is often characterized by a tendency toward a conceptual molecularization of the environment in which it is seen to act as an add-on to the genome, affecting health with varying degrees of determinism. Thus, notwithstanding its potential to inspire complex 'biosocial' notions of health and illness, current research in environmental epigenetics might also engender novel forms of biological essentialism, particularly if epigenetic modifications are framed as permanent bodily marks that determine the potentials of individuals and groups who have been exposed to potentially 'harmful' environments (Müller et al, 2017; Lock, 2013). Environmental epigenetics, then, may have shifted the timelines and substrates of essentialism, but many uncertainties remain as to the extent to which human biology is conceived of as 'plastic' beyond a variety of 'critical windows' during development.

However, epigenetic understandings of the environment as bioactive have significantly transformed twentieth-century notions of risk in public health, which were predicated on the analysis of separate distal (e.g., exterior) and proximal (e.g., internal) sources of risk and their relative impacts on health outcomes. These models are being upset, as both distal sources of risk, seen as embodied 'miniaturized environments', and proximal sources of risk are now conceived of as molecular and interactive through epigenetic logics (Lloyd and Raikhel, 2018; Landecker and Panofsky, 2013). In many respects, all sources of risk are rendered 'proximal' through these logics. Accordingly, there remain important questions about the extent to which these logics will ultimately draw attention to 'the causes of the causes', for instance social disadvantage as the underlying cause behind epigenetic traits induced by stress, poor nutrition, or toxic exposures, or whether research will exclusively consider factors on a molecular scale (Lock, 2015). Consequently, concerns have been raised that epigenetic studies might eventually lead to impoverished notions of the biosocial and might suggest too simple explanations and solutions for complex social problems. For example, a number of researchers have pointed out that maternal bodies and behaviors have been staged as epigenetically meaningful in ways that preclude the consideration of the wider social and material environments in which mothers and children live (Richardson, 2015; Warin et al, 2016; Kenney and Müller, 2017; Chiapperino and Panese, 2018).

In order to better understand how material and social environments are being conceived of, operationalized, and translated in environmental epigenetics research, careful and critical empirical research is required. Given the relative absence of such scholarship, we have a limited understanding of how epigenetic knowledge claims are being constructed in the lab, how environments and bodies are conceived of and accounted for in research practices, how such claims are negotiated within scientific communities, and how they are taken up by medical professionals, the public, and policy makers. This special issue thus arises from the important need to attend more closely to the complexities of environmental epigenetics research in practice: the ways in which environments of many kinds are being factored into research agendas and their consequences for understandings of human development and for theorizing how humans are materially shaped by their experiences. Through a series of empirical engagements with epigenetics research, the six articles in this special issue trace the production and use of this scientific knowledge and the objects it is studying. 
The empirical contributions to this special issue are preceded by a conceptual piece by Jörg Niewöhner and Margaret Lock. In "Situating Local Biologies" these authors extend the notion of "local biologies" (Lock 1993), a concept that was instrumental in recent studies of how "local knowledge about human biology is informed by the social, and the material in turn informs the social" (Niewöhner and Lock, 2018). "Situated biologies" draws attention to the dynamic interactions between humans and their environments as well as to how these are understood and are contingent upon knowledge practices, including those within the laboratories where human-environment entanglements are studied. Niewöhner and Lock raise questions as to what "situated" might look like in different studies (e.g., a rich life history, a psychological scale paired with a tissue sample) and to what extent different measures could speak to one another and to the satisfaction of whom. They further evoke considerations about what body is being studied (e.g., model organisms, geographically specific human populations) and what we can learn (or not) from those modes of knowledge production in such a way that epigenetic research might be applicable to any one body's one person's - experiences and health profile vis-à-vis another. The empirically based studies in this special issue respond to these questions by tracing epigenetic practices from the lab to the clinic, examining how situated bodies and lives are produced, and scrutinizing the analytic gazes that accompany environmental epigenetics research.

Martine Lappé's "The paradox of care in behavioral epigenetics: Constructing early-life adversity in the lab" traces the forms of care enacted in epigenetic research on early-life adversity. Based on over two years of ethnographic research, her analysis points to tensions between researchers' caring practices in the lab and their measurement of early-life adversity as a discrete variable in the form of maternal interaction, neglect, and abuse in their studies with model organisms. She argues that these tensions suggest a "paradox of care" (Lappé, 2018) that is actively shaping how epigenetic knowledge is produced and its impacts beyond the lab. Lappé's examination of the complex roles that conceptions and enactments of care play throughout the research process provides key insights into how research on maternal care in model organisms can shape understandings of human health and our social expectations of mothers.

Stephanie Lloyd and Eugene Raikhel's “'It was there all along': Situated uncertainty and the politics of publication in environmental epigenetics" explores an instance of how the meaning and interpretation of epigenetic data can shift swiftly in this fast-changing field. Like Lappé's contribution, Lloyd and Raikhel's article is based on long-term ethnographic research in an environmental epigenetics lab. They follow the changing significance of a set of findings as it sat, untouched, in a computer for several years. Throughout this time, what had previously been understood as artifacts of the research method were reinterpreted as findings. Researchers' reappraisals were in part due to the changing basis of scientific knowledge but also to their considerations of the claims that could be made from the data, based on the lab's specific profile of knowledge production. Their article situates environmental epigenetics knowledge production amid the constraints of tissue samples, the translation of findings from model organisms to humans, and requirements to claim novel findings in this emerging discipline.

Ruth Müller and Georgia Samaras' "Epigenetics and aging research: Between adult malleability and early life programming" moves beyond the scale of the individual lab and explores the epistemic and biopolitical formations that arise as knowledge propositions from 
epigenetics are taken up within the specific research field of aging research. Based on a literature analysis, participant observation at international conferences, and interviews with researchers, they show that epigenetics has become central to two distinctly different conceptualizations of aging within the field. These two perspectives do not only differ epistemically, but also with regard to the kinds of clinical, social, and political responses to the 'aging society' researchers imagine. They conclude that epigenetics "can participate in heterogeneous epistemic formations with diverging biopolitical momenta" (Müller and Samaras, 2018) and call for a more detailed exploration of its uptake in different research fields.

Sahra Gibbon's “Calibrating cancer risk, uncertainty and environments: The contexts between genetics and epigenetics in southern Brazil" draws on extended ethnographic research in Brazil and examines how reasoning about cancer genetics, low-risk mutations, environments, and epigenetics interact and "resourcefully populate" (Gibbon, 2018) gaps in understandings of risk, with consequences for changing models of research and care. She traces how, in "the spaces between identifying genetic markers and conditional cancer risk” (Gibbon, 2018), different environments are being evoked and negotiated as meaningful factors of disease risks among research and clinical communities, patients, and their families. Her work concludes that, in a context where genetics alone does not provide satisfying answers for patients or practitioners, environments and genes are already being meaningfully calibrated in order to account for risks that seem to go beyond the gene.

The special issue is concluded by a commentary by Rayna Rapp, in which she deftly explores the key themes emerging from the conceptual and empirical contributions of the special issue and their implications for our current understanding of situated biosocial accounts of body, health, and illness in contemporary epigenetic research. She locates the theories and practices of environmental epigenetics among biosciences old and new, drawing attention to the persistent "promissory notes of future perfectibility through scientific research and its translation into medical practice, continually upended by its uneven benefits and dead-ends" (Rapp, 2018) within this research in particular.

Together, the different contributions of this special issue move beyond enthusiasm and skepticism and towards a careful empirical exploration of the situated epistemic, social, and political landscapes that are emerging with environmental epigenetics. They contribute a situated understanding of the intricacies of how key concepts in environmental epigenetics are produced and the extent to which natural and social scientists' conceptual tools for studying situated bodies are compatible. Given the mutual interests of environmental epigenetics researchers and social scientists in the embodiment of social and material environments (Guthman and Mansfield, 2012; Roberts and Sanz, 2018), an understanding of these intricacies is essential if repeated calls for potential collaborative work, or "experimental entanglements" (Fitzgerald and Callard, 2015), are to be realized. The empirical studies included in this special issue provide a starting point from which to consider what it might mean to actively collaborate with environmental epigeneticists. This empirical form of analysis can serve as the basis for ongoing - and critical, in a variety of senses of this term - engagement with these powerful research agendas.

Consequently, this special issue provides us with insights into a highly dynamic research field, which is characterized not only by controversies and high-running hopes, but also by the cautious work of figuring out what it might mean to do justice to the complex 
entanglements of the social and the biological in experimental practice. In doing so, we draw attention to important shifts in the biosciences that frame life as a biosocial process, along with the current limitations of these shifts, and contribute to a better understanding of how these novel accounts are being produced and have begun to circulate in science and society.

\section{Acknowledgements}

With thanks to Des Fitzgerald, Martine Lappé, and Martyn Pickersgill for their constructive feedback on an earlier draft of this text and to Catherine Waldby and Ayo Wahlberg for their support in bringing this special issue through to publication. Many of the articles included in this special issue emerged from the workshop "Environmental Epigenetics and the Promise of Biosocial Science" (2015), organized by Stephanie Lloyd and Eugene Raikhel, which was funded by the Brocher Foundation. We would like to thank all workshop participants for their insights into the questions addressed in this special issue.

\section{About the Authors}

Stephanie Lloyd is an associate professor in the Department of Anthropology at Université Laval. Her work is informed by a social and historical study of molecular biology, neuroscience, and psychiatry. She co-editor (with Maurizio Meloni, John Cromby, and Des Fitzgerald) of The Palgrave Handbook of Biology and Society.

Ruth Müller is Assistant Professor of Science and Technology Policy at the Munich Center for Technology in Society, TU Munich. Her work explores interactions between science, society, and policy, with a focus on the life sciences. Currently, she investigates i.a. how research approaches from environmental epigenetics are adopted and adapted in different research fields, with a specific interest in how questions of social inequality are enacted in and through environmental epigenetics.

\section{References}

Chiapperino, L. and Panese F. (2018) Gendered imaginaries: Situating knowledge of epigenetic programming of health. Sociology of Health \& Illness 40(7): 1233-1249.

Fitzgerald, D. and Callard, F. (2015) Social science and neuroscience beyond interdisciplinarity: Experimental entanglements. Theory, Culture \& Society 32(1): 3-32.

Gibbon, S. (2018) Calibrating cancer risk, uncertainty and environments: Genetics and their contexts in southern Brazil. BioSocieties. https://doi.org/10.1057/s41292-017-0095-7.

Guthman, J., and Mansfield, B. (2012) The implications of environmental epigenetics: A new direction for geographic inquiry on health, space, and nature-society relations. Progress in Human Geography 37(4): 486-504

Kenney, M., and Müller, R. (2017) Of rats and women: Narratives of motherhood in environmental epigenetics. BioSocieties 12(1): 23-46.

Lappé, M. (2018) The paradox of care in behavioral epigenetics: Constructing early-life adversity in the lab. BioSocieties. https://doi.org/10.1057/s41292-017-0090-z 
Lappé, M., and Landecker, H. (2015) How the genome got a life span. New Genetics and Society 34(2): $152-176$.

Landecker, H., and Panofsky, A. (2013) From social structure to gene regulation, and back: A critical introduction to environmental epigenetics for sociology. Annual Review of Sociology 39(1): 333-357.

Lloyd, S., and Raikhel, E. (2018) Environmental epigenetics and suicide risk at a molecular scale. In S. Hilgartner, S. Gibbon, B. Prainsack, and J. Lamoreaux (eds.) Handbook of Genomics, Health and Society. London: Routledge.

Lock, M. (1993) Encounters with Aging: Mythologies of Menopause in Japan and North America. Berkeley and Los Angeles: University of California Press.

Lock, M. (2013) The lure of the epigenome. Lancet 381: 1896-1897.

Lock, M. (2015) Comprehending the body in the era of the epigenome. Current Anthropology 56(2): 151-177.

Meloni, M. (2014) Biology without biologism: Social theory in a postgenomic age. Sociology 48(4): 731-746.

Müller, R., Hanson, C., Hanson, M., Penkler, M., Samaras, G., Chiapperino, L., Dupré, J., Kenney, M., Kuzawa, C., Latimer, J., Lloyd, S., Lunkes, A., Macdonald, M., Meloni, M., Nerlich, B., Panese,F., Pickersgill, M., Richardson, S., Rü egg, J., Schmitz, S., Stelmach, A., and Villa, P.-I. (2017) The biosocial genome? Interdisciplinary perspectives on environmental epigenetics, health and society. EMBO Reports. https://doi.org/10.15252/embr.201744953.

Müller, R. and Samaras, G. (2018) Epigenetics and aging research. Between adult malleability and early life programming. BioSocieties. https://doi.org/10.1057/s41292-017-0091-y.

Niewöhner, J. and Lock, M. (2018) Situating local biologies: Anthropological perspectives on environment/ human entanglements. BioSocieties. https://doi.org/10.1057/s41292-017-0089-5.

Pickersgill, M. (2017) Epistemic modesty, ostentatiousness and the uncertainties of epigenetics: On the knowledge machinery of (social) science. The Sociological Review 64(1): 186-202.

Rapp, R. (2018) Epigenetics at work. BioSocieties. https://doi.org/10.1057/s41292-017-0093-9.

Richardson, S. S. (2015) Maternal bodies in the postgenomic order: Gender and the explanatory landscape of epigenetics. In S. S. Richardson and H. Stevens (eds.) Postgenomics: Perspectives on Biology After the Genome (pp. 210-231). Durham and London: Duke University Press.

Roberts, E. F. and Sanz, C. (2018) Bioethnography: A how-to guide for the twenty-first century. In The Palgrave Handbook of Biology and Society (pp. 749-775). London: Palgrave Macmillan.

Waggoner, M. R. and Uller, T. (2015) Epigenetic determinism in science and society. New Genetics and Society 34(2): 177-195.

Warin, M., Moore, V., Davies, M., and Ulijaszek, S. (2016) Epigenetics and obesity: The reproduction of habitus through intracellular and social environments. Body \& Society 22(4): 53-78. 